\title{
Why is carbon leakage for energy-intensive industry hard to find?
}

\author{
Shon Ferguson ${ }^{1} \cdot$ Mark Sanctuary $^{2}$
}

Received: 18 September 2017 / Accepted: 20 May 2018 / Published online: 1 June 2018

(C) The Author(s) 2018

\begin{abstract}
A number of researchers have found that imports by pollution heavy industries do not increase in response to tighter pollution policy. We empirically evaluate the impact of an sudden and unexpected increase in Swedish electricity prices in the 2000s on the imports of intermediate inputs by Swedish manufacturers. We find that imports declined as domestic electricity prices rose for firms with the most electricity-intense in-house production. We rationalize these findings by developing a simple model of trade in intermediate inputs, which illustrates that energyintense firms may decrease imports if it is sufficiently difficult to substitute between domestic- and foreign-sourced inputs as domestic energy prices rise. The offshoring mechanism which we identify can help to reconcile conflicting empirical results in the carbon leakage and pollution haven literature, and also has implications for determining the extent to which energy intense trade-exposed sectors should be exempt from domestic climate change policy.
\end{abstract}

Keywords Carbon leakage $\cdot$ Pollution haven $\cdot$ Energy $\cdot$ Importing

JEL Classification $\quad \mathrm{D} 21 \cdot \mathrm{F} 14 \cdot \mathrm{F} 18 \cdot \mathrm{Q} 40$

Mark Sanctuary

mark.sanctuary@ivl.se

Shon Ferguson

shon.ferguson@ifn.se

1 Research Institute of Industrial Economics, Box 55665, 10215 Stockholm, Sweden

2 IVL Swedish Environmental Research Institute, Box 21060, 10031 Stockholm, Sweden 


\section{Introduction}

Increasingly stringent unilateral climate policy, it is argued, will lead to leakage of greenhouse gas emissions: increased emissions from unconstrained regions due to regulations undertaken in constrained regions. Leakage would then erode the effectiveness of climate regulations and undermine national industrial interests, i.e., competitiveness. Carbon leakage is one of the main arguments against more ambitious climate policies.

Despite an intuitive appeal, empirically evaluating the leakage mechanism has proven difficult. The same applies to the impact of environmental regulation and international trade flows more generally, i.e., 'pollution havens', of which carbon policy leakage is a special case. An issue at the heart of this discussion is the impact of environmental regulation on the location of pollution-intensive production. Counter-intuitive empirical findings have undermined efforts to build the consensus required to develop appropriate policy responses.

In this paper, we examine the impact of increasing energy prices on firm offshoring activities. Changes in offshoring activities are one measure of carbon leakage: domestic climate policy increases the cost of domestic energy and induces firms to substitute towards cheaper inputs produced in a foreign region unconstrained by climate policy. This would then lead to an increase in imports. This increase in imports results in carbon leakage if firms substitute towards imports that have a higher carbon intensity than in-house or domestically produced inputs. The magnitude of this offshoring effect is an open empirical issue. ${ }^{1}$

We develop a simple model of trade in intermediate inputs, which illustrates that energy-intense firms may decrease imports if it is sufficiently difficult to substitute between domestic- and foreign-sourced inputs as domestic energy prices rise. Two countervailing forces determine the firm's import response. The first is the substitution effect, where higher domestic energy prices induce firms to substitute towards foreign-sourced inputs for a given level of firm output. ${ }^{2}$ This effect alone would lead a firm to increase its imports, for a given level of the firm's output. The second is the scale effect, where higher domestic energy prices result in higher production costs that reduces the firm's optimal level of output, which in turn results in a reduction in firm demand for foreign-sourced inputs. The strength of the scale effect increases when a firm cannot fully mitigate the domestic factor price shock by substituting towards foreign-sourced inputs. This would be the case if substitution between domestic and imported factors was difficult due to the cost of reconfiguring supply chains, for example. Moreover, energy-intensive firms have a higher exposure to domestic energy price shocks, suggesting that the scale effect could dominate for

\footnotetext{
1 Trade flow leakage can also occur through trade in final goods. For example, domestic climate policies result in the offshoring of production of a final good, which are then exported back to domestic consumers. Or domestic final good producers can no longer compete and reduce exports, thereby bypassing the domestic economy completely.

${ }^{2}$ Higher energy prices may also induce firms to switch towards less energy-intense domestically sourced inputs, but this is a mechanism for which we lack data.
} 
these firms. Imports by the most energy-intense firms would thereby decrease with a domestic energy price increase. Contrasting the relative importance of the scale and substitution effect for different firm energy intensities is a novel empirical issue and is the focus of our study.

We test our prediction with rich firm-level data covering the universe of Swedish manufacturing firms, and the products imported by each firm described at the sixdigit combined nomenclature (CN) product level over the period 2001-2008 inclusive. An uncommon feature of the data is that we observe firm-level annual expenditures on, and quantities of, purchased electricity, which allows us to compute the unit value electricity price (EP) for each firm.

We exploit an unprecedented rise in EPs from 2003 onwards as the EP paid by Swedish firms quickly caught up to the European OECD average due to several factors. This increase began with a particularly dry summer in 2002, which constrained hydro-power production in the winter of 2003. This rise in EPs was sustained due a combination of factors, such as sporadic closures of nuclear power production in Sweden, the impact of the Emissions Trading System, and also the gradual integration of the Nordic electricity network with continental Europe. Since the electricity market in Sweden is deregulated and firms can hedge, the sharp and sustained rise in spot market prices resulted in a corresponding, albeit heterogeneous, increase in EPs paid by Swedish firms, including heavy, energy-intensive manufacturing industries exposed to import competition.

Our empirical approach exploits idiosyncratic, EP variation between firms and within firms over time, variation in the electricity intensity of individual firms, and the heterogeneity of imported products to identify the impact of the electricity price increase on imports. This makes it possible to construct a highly dis-aggregated estimate of the domestic electricity use avoided by a firm through the use of imported products, disentangle the effects that determine a firm's import decision, and identify the impact of the electricity price increase on the quantity of imports at the product level. Swedish electricity is produced predominantly without fossil fuel, e.g., hydro-power and nuclear power. An increase in importing resulting from higher electricity prices is, therefore, likely to increase global emissions as production is moved abroad to jurisdictions where electricity production is more carbon-intensive. Hence, our study clarifies a mechanism through which a change in the domestic energy price affects imports, and the potential for carbon policy leakage. This study is the first, that we are aware of, to examine this particular leakage mechanism using firm-product-level data.

Our regressions show that for the most electricity-intense firms, ${ }^{3}$ an increase in a firm's EP results in a decline of the firm's imports. In the top electricity intensity quartile, a 30\% increase in the firm's EP leads the firm to decrease the quantity of an imported product by $5 \%$. This effect is statistically significant, although the economic magnitude of the effect is small. This suggests that the scale effect dominates the substitution effect for energy intense firms. In contrast, for firms in the

\footnotetext{
3 A firm's electricity intensity is measured in terms of the ratio of the quantity of electricity employed by the firm to firm value added.
} 
second electricity intensity quartile, a 30\% increase in the firm's EP leads the firm to increase the quantity imported product by $2.5 \%$. There are several potential reasons why we find quantitatively small impacts. First, the largest and most electricityintense firms likely engaged in hedging strategies that insulated themselves against the rise in electricity prices. Second, firms may not have believed the increase in electricity prices to be permanent and thus opted to not pursue any adaptations. In this sense, our estimates may be viewed as a lower bound on impact of a carbon tax on leakage. A third reason is that firms may pass-through the marginal cost shock.

Our paper contributes to the literature on carbon leakage by studying a channel that acts through firm-level offshoring of intermediate stages of production. There is relatively little evidence of the importance of this channel. An exception is a recent contribution by Cole et al. (2017) using Japanese firm-level data to study the "pollution outsourcing hypothesis". In their study, it is outsourcing that causes a reduction in the carbon emissions of the firm. In contrast, our study uses the increase in electricity prices to estimate the firm's propensity to import inputs. Evidence of carbon leakage via trade flows and pollution havens more generally is inconclusive in the previous studies. Larger and more significant trade flow effects are found for less pollution-intensive industries, see Ederington et al. (2005), Levinson and Taylor (2008), and Levinson (2010). An explanation that has been put forward is that pollution-intensive industries tend to be relatively immobile, while less pollutionintensive industries tend to be more labor-intensive and geographically "footloose". We examine this mechanism and find some support for this effect, although it does not affect the robustness of our findings.

There are a few econometric studies of carbon leakage. The evidence for climate policy leakage is an open empirical question that ex post-studies of leakage are few, and that ex ante studies lead to widely differing results (Monjon and Quirion 2010). Econometric studies have not revealed the carbon leakage predicted by ex ante, computable general equilibrium models (Branger and Quirion 2014). Aldy and Pizer (2015) infer the impact of a future unilateral 15 USD per ton $\mathrm{CO}_{2}$ price on domestic US production and net imports using variation in historical energy prices, an econometric approach that is similar to ours, although their analysis uses sector-level data. Their data cover 450 US industries at the 4-digit industry level. They find small effects on net imports. They also find that energy-intensive firms do not respond to higher energy prices by proportionally consuming more imports.

An econometric analysis by Aichele and Felbermayr (2015) estimates the degree of carbon leakage resulting from the Kyoto Protocol with sectoral trade data and emission data covering fifteen sectors and forty countries. Their estimates suggest that Kyoto has led to leakage: an increase of $8 \%$ in the embodied carbon of imports from noncommitted to committed countries. ${ }^{5}$ They find the largest leakage effects in the more carbon-intensive sectors. ${ }^{6}$ In contrast, Chevallier and Philippe Quirion (2017) conduct

\footnotetext{
4 The review by Cherniwchan et al. (2017) discusses the pollution outsourcing mechanism, as well.

5 The $8 \%$ increase in the embodied carbon of imports implies a leakage rate of over $100 \%$.

6 These carbon-intensive sectors are basic metals, chemicals and petrochemicals, non-metallic mineral products, transport equipment, machinery or pulp, and paper.
} 
an econometric analysis of carbon leakage resulting from the EU Emission Trading Scheme (ETS) on the cement and steel sectors. They find no evidence that the EU ETS has had any effect on net imports in these energy-intensive sectors.

The econometric study of carbon leakage is conceptually distinct from studies of carbon leakage using calibrated simulations of future climate policy (computable general equilibrium models). These approaches have been deployed to provide aggregate ex ante estimates of leakage, and predictions vary with the parameterization of the models. There are a large number of papers in this area of the literature, and most studies find that climate policy will result in some positive level of leakage, especially for energy-intensive trade-exposed primary good sectors, e.g., the metals, cement, glass, and chemicals. Branger and Quirion (2014) review this literature.

Our results are complementary to Baylis et al. (2014), who show analytically that a carbon cost shock can lead to "negative leakage". While our empirical results provide support for the idea of negative leakage, the mechanism that we test differs from their work. In Baylis et al. (2014), the negative leakage mechanism is a general equilibrium effect: the taxed sector substitutes away from carbon into clean inputs, the clean input becomes more scarce, shrinking the other sector and thereby reducing its emissions. We focus on a mechanism where substitution between domestic inputs and "dirty" foreign inputs is difficult, which affects the firm's marginal cost and thereby the firm's demand for foreign inputs. This is a firm-level effect, but, in aggregate, it could lead to negative leakage.

The paper continues with a conceptual framework in Sect. 2, followed by a description of the Swedish electricity market in Sect. 3. The data and descriptive statistics are discussed in Sect. 4; the empirical specification and the main results of the analysis are described in Sect. 5. The conclusion is drawn in Sect. 6.

\section{Conceptual framework}

We present a framework that illustrates the impact of higher domestic energy prices on a firm's energy-intensive imports. We present this framework to clarify the mechanism which we have in mind.

A profit-maximizing firm $i$ produces a quantity of output $y_{i}$ that is sold on international markets. Firms are price takers and sell their output at the world price $p$. Production of this output requires inputs of energy $e_{i}$ and other inputs sourced abroad $x_{f i}$. The firm's production function is thus $y_{i}=F\left(e_{i}, x_{f}\right)$, which is increasing and concave in both arguments. $x_{f i}$ is produced using foreign energy and the domestic and foreign price of energy may vary separately. We denote functions with upper case and levels with lower case.

The solution to the firm's cost minimization problem yields conditional factor demand functions $E_{i}\left(y_{i} ; \rho_{i}, \rho_{f}\right)$ and $X_{f i}\left(y_{i} ; \rho_{i}, \rho_{f}\right)$, where $\rho_{i}$ is the price the firm pays for energy in-house and $\rho_{f}$ is the price of energy paid by producers of $x_{f i}$ abroad. The firm's total cost function is therefore:

$$
C_{i}\left(y_{i} ; \rho_{i}, \rho_{f}\right)=\rho_{i} E_{i}\left(y_{i} ; \rho_{i}, \rho_{f}\right)+\rho_{f} X_{f i}\left(y_{i} ; \rho_{i}, \rho_{f}\right) .
$$


Supply is competitive and the firm maximizes profits by choosing a level of output to satisfy:

$$
\max _{y_{i}} p y_{i}-C_{i}\left(y_{i} ; \rho_{i}, \rho_{f}\right)
$$

This yields the supply function $Y_{i}\left(p, \rho_{i}, \rho_{f}\right)$. Market clearing determines the equilibrium price of the firm's output $p^{*}$, and the firm's equilibrium profit-maximizing output level $y_{i}^{*} \equiv Y_{i}\left(p^{*}, \rho_{i}, \rho_{f}\right)$. The optimal quantity of foreign-sourced inputs in production is then $x_{f i}^{*} \equiv X_{f i}\left(y_{i}^{*}, \rho_{i}, \rho_{f}\right)$.

An increase in the domestic energy price $\rho_{i}$ affects the firm's demand for $x_{f i}$ through a substitution and scale effect:

$$
\left.\frac{\mathrm{d} X_{f i}}{\mathrm{~d} \rho_{i}}\right|_{p_{i}^{*}}=[\underbrace{\left(\frac{\partial X_{f i}}{\partial \rho_{i}}\right)_{\mathrm{d} y_{i}=0}}_{\text {Substitution effect }}+\underbrace{\frac{\partial X_{f i}}{\partial y_{i}} \frac{\partial Y_{i}}{\partial \rho_{i}}}_{\text {Scale effect }}]_{p=p^{*}} .
$$

The first term on the right-hand side of Eq. (3) captures the substitution effect. Holding firm output constant $\left(\mathrm{d} y_{i}=0\right)$, this term is positive if foreign- and domestically sourced intermediate inputs are substitutes and negative if they are complements.

The second term on the right-hand side of Eq. (3), comprised of two parts, captures the scale effect. The sign of the scale effect is ambiguous. ${ }^{7}$ The scale effect is negative if $x_{f i}$ is a sufficiently poor substitute for $e_{i}$. An increase in $\rho_{i}$ would thereby increase the firm's marginal cost and output price, which leads firms to reduce their optimal output level $y_{i}^{*}$, which leads to a reduction in the demand for imports. If $x_{f i}$ is a perfect substitute for $e_{i}$, then the firm's marginal cost is unaffected by an increase in $\rho_{i}$, and the firm is able to mitigate the domestic cost shock using foreign inputs. In this case, only the substitution effect will operate, which leads to an increase in the firm's demand for imports.

A negative scale effect is sometimes referred to as a loss of a firm's "competitiveness" in the sense that other firms increase their output to make up for the reduction in $y_{i}$. This could lead to carbon leakage via trade in final goods if it is foreign firms that make up for this reduced output. Global emissions would increase if foreign firms produce with a more carbon-intensive technology. However, carbon leakage via trade in final goods lies outside the scope of this study.

Although the net effect of the substitution and scale effects is ambiguous, in general, we can make some predictions about the relationship between the firm's

\footnotetext{
7 Nagatani (1978) shows that the scale effect is negative when there is an input cost shock and the input is a normal or inferior good.
} 
own energy intensity and its propensity to import inputs when the domestic energy price rises.

We posit that the cross-price elasticity of foreign-sourced intermediate inputs with respect to domestic energy prices is decreasing with the energy intensity of production. If $x_{f i}$ and $e_{i}$ are sufficiently poor substitutes, then energy intense firms will not import the most, and may reduce imports, in response to a domestic energy price increase. We now impose a specific functional form for $p^{*}$ to illustrate the impact of energy intensity on the firm's propensity to import. Firms deploy a constant elasticity of substitution (CES) production technology:

$$
y_{i}=\left[\theta_{i} e_{i}^{\frac{\gamma-1}{\gamma}}+\left(1-\theta_{i}\right) x_{f}^{\frac{\gamma-1}{\gamma}}\right]^{\eta \frac{\gamma}{\gamma-1}},
$$

where $\theta_{i} \in(0,1)$ captures the energy intensity of production of the firm; $\eta \in(0,1)$ captures the returns to scale; $\gamma$ captures the constant elasticity of substitution between the two inputs. The solution to the firm's cost minimization problem yields conditional factor demands:

$$
\begin{aligned}
& E_{i}\left(\rho_{i}, \rho_{f} ; y_{i}\right)=\frac{\rho_{i}^{-\gamma} Y_{i}^{\frac{1}{\eta}}}{\left[\theta_{i} \rho_{i}^{1-\gamma}+\left(1-\theta_{i}\right) \rho_{f}^{1-\gamma}\right]^{\frac{\gamma}{\gamma-1}}} \\
& X_{f i}\left(\rho_{i}, \rho_{f} ; y_{i}\right)=\frac{\rho_{f}^{-\gamma} Y_{i}^{\frac{1}{\eta}}}{\left[\theta_{i} \rho_{i}^{1-\gamma}+\left(1-\theta_{i}\right) \rho_{f}^{1-\gamma}\right]^{\frac{\gamma}{\gamma-1}}} .
\end{aligned}
$$

Figure 1 illustrates the substitution and scale effect as defined by Eq. (3) across a firm's energy intensity $\theta$ and three values of the elasticity of substitution between energy and imported inputs: $\gamma=0$, a Leontief technology; $\gamma=1$, a Cobb-Douglas technology; $\gamma=2$. The other parameter values are: $\eta=\frac{1}{2} ; \rho_{i}=\rho_{f}=1 ; p_{i}=1$.

In Fig. 1a, increasing the energy intensity of the firm increases the firm's propensity to substitute towards foreign inputs for $\gamma>0$ : the substitution effect is increasing in $\theta$. On the other hand, in Fig. 1a, the scale effect is increasingly negative in $\theta$ for $\gamma>0$. The total partial effect (the sum of the substitution and scale effects) is plotted in Fig. 1b. For the parameter values chosen, the scale effect dominates the substitution effect for higher levels of $\theta$, suggesting that energyintense firms reduce imports in $\rho_{i}$.

The intuition for this result can be gained by comparing the two cases of substitutability between $e_{i}$ and $x_{f i}$. Consider first the case where firms employ a Leontief technology $(\gamma=0)$. There is no substitution effect and only the scale effect operates. An increase in $\rho_{i}$ will result in an increase in the firm's marginal cost schedule and its profit-maximizing output will shrink, leading to a decrease in imports. 

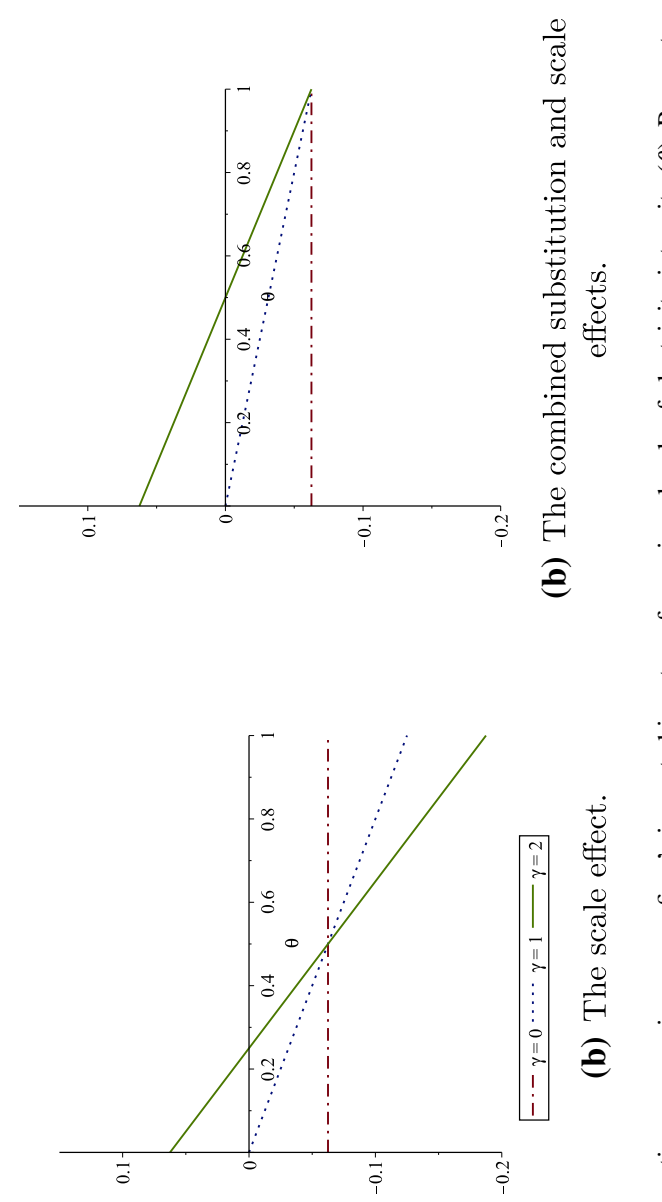

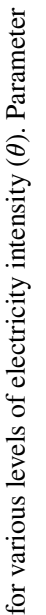
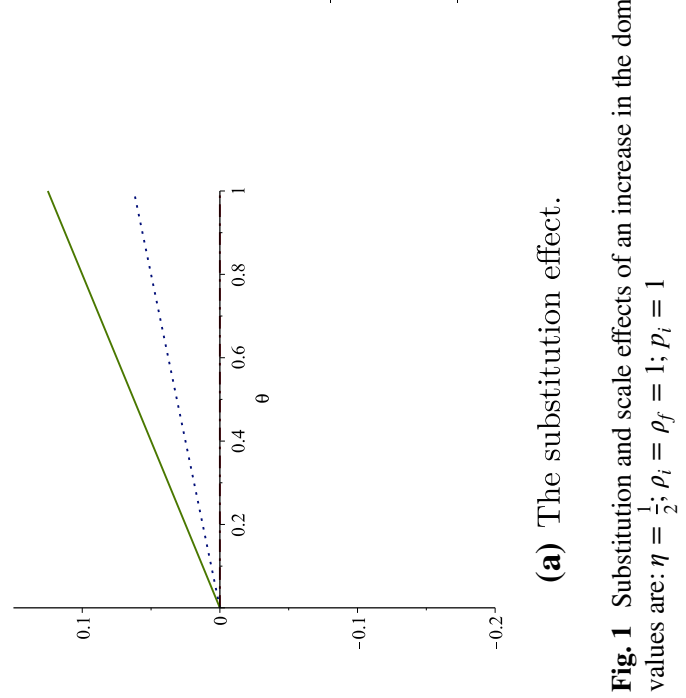
In the other case, input factors are substitutes $(\gamma=2)$. Now, both the scale and substitution effects operate. The substitution effect is increasing in $\theta$ : the marginal gains from employing imports are increasing in the firm's energy intensity. However, the scale effect is decreasing in $\theta$ : the marginal effect of the factor price increase on the firm's marginal cost is increasing in $\theta$.

The hypothesis which we test is: Energy-intense firms have a lower propensity to increase imports with a domestic energy price increase.

We have discussed the concepts, assuming that downstream firms are price takers. If shocks to marginal cost can be passed through output prices, this would dampen the scale effect, since Eq. (2) implies that a rise in price allows for a higher profitmaximizing level of production. In the extreme case, with full pass-through of the marginal cost shock to prices, firms' equilibrium output would be unchanged. Thus, any prevalence of pass-through would work against finding any negative effects of higher domestic energy prices on imports in the subsequent empirical analysis.

\section{The Swedish electricity market and climate policy}

Sweden participates in the Scandinavian wholesale electricity market. Firms can, therefore, purchase electricity at the market spot price plus a transmission fee and retailer margin. ${ }^{8}$ Firms can also manage the risk of electricity price changes by engaging in longer term contracts and hedging. Thus, the EP incurred by many firms is distinct from the daily electricity spot price, which saw a dramatic spike in the inter-day price at the end of 2002 (prices reach over 1 SEK/KWh), see Appendix Fig. 3. The spike in electricity prices lasted several months, well into 2003.

Firms' exposure to this price spikes was mitigated, to varying degrees, by longterm contracts and futures contracts. Some firms would have written contracts that effectively mitigated their exposure to this electricity price spike, whereas others would have faced higher electricity costs as their contracts expired. The use of electricity contracts reduces and/or delays the impact of the price shock on the firms cost structure. ${ }^{9}$ Although we cannot observe firms' hedging strategies, we expect that large and electricity-intense firms were less exposed to the initial price shock, which would work against us finding any effects. Forward pricing contracts on the electricity futures market extend up to 3 years, which implies that an increasing share of firms would be exposed to higher EPs by 2006, 3 years after the sharp increase in the domestic electricity spot price.

The 2002-2003 increase in Sweden's electricity spot price was driven by several factors. For one, the summer of 2002 was particularly dry, which led to decreased hydro-power production in the winter of 2003. Levels in hydro-power magazines did

\footnotetext{
${ }^{8}$ Sweden deregulated its electricity market on January 1, 1996. Electricity producers sell on the wholesale market Nord Pool. A number of retailers sell electricity contracts to industrial and household consumers.

9 There is no scope for price discrimination among customers at the wholesale level. However, the transmission fees and retailer margins may vary by customer, and the lower prices paid by larger firms largely reflect differences in negotiated transmission fees and retailer margins.
} 


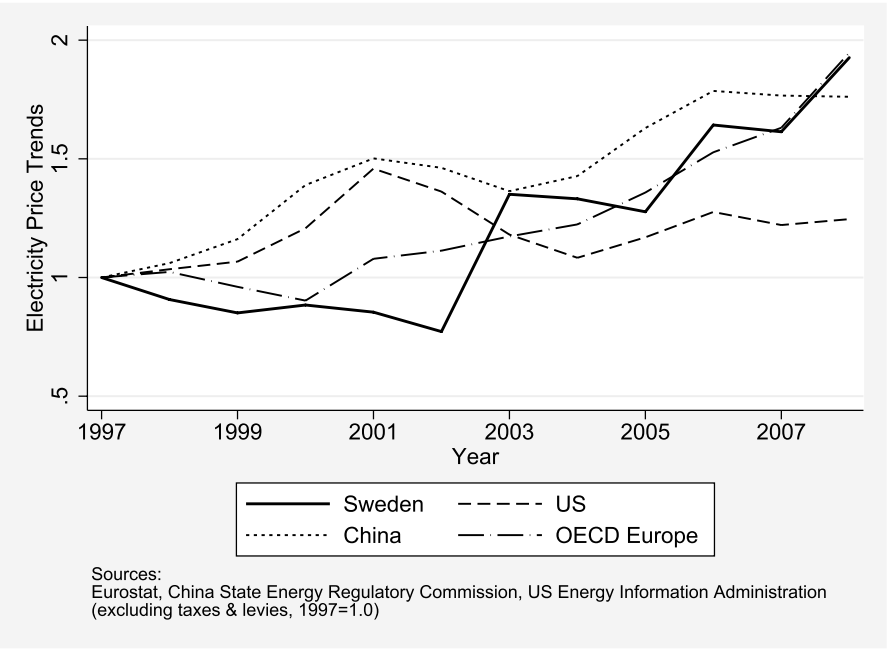

Fig. 2 Average annual electricity nominal prices paid in Sweden and Sweden's most important countries/regions of import origin. Swedish industrial electricity prices increased in 2003, converging towards levels paid in the EU15. Sweden's top non-EU15 import origins had low and stable electricity prices over the 2001-2008 period, although prices vary significantly across firms within many countries. Source: Eurostat, US Energy Information Administration

not return to normal until the end of 2004. This had an important impact on Swedish electricity prices with hydro-power meeting just under half of Swedish electricity demand. Figure 4 in the Appendix shows that the forward market did not anticipate this initial shock: the price of 2003 and 2004 forward contracts increased; and the price of 2004 forward contracts did not fall back to pre-2002 levels.

High spot market prices continued after the initial shock due to several factors. First, the sporadic closures of nuclear power production during the period further constricted electricity supply with nuclear power meeting just under half of Sweden's electricity demand. ${ }^{10}$ Second, Nordic electricity networks became more integrated with markets in continental Europe, which tended to have higher prices. Third, the launch of the European Union's Emission Trading System (EU ETS) in 2005 may have had an impact on electricity prices across Europe. ${ }^{11}$ The result of all these factors meant that the average EP paid by Swedish manufacturing quickly caught up to the European OECD average after a long period of sustained low prices. At the same time, EPs across Sweden's most important non-European

\footnotetext{
10 In 2008, 47\% (42\%) of electricity demand was met by hydro-power (nuclear power).

11 Swedish electricity production is dominated by low emission technology, namely hydro-power and nuclear power. However, any shortfall in hydro or nuclear generation is compensated by fossil fuel-driven generation. Electricity prices can, therefore, be driven by the marginal cost of coal or gas when electricity demand is high enough, and it is the marginal cost of fossil fuels that are affected by the EU ETS. Sorting out the impact of the EU ETS on the Swedish electricity market is a research question in its own right, see Fell (2010).
} 
Table 1 Firm descriptive statistics

\begin{tabular}{llllll}
\hline & Obs & Mean & Std. dev. & Min. & Max. \\
\hline $\ln \left(x_{f, i, p, t}\right)$ & & & & & \\
$\quad$ Import quantity (kg) & 411,854 & 220 & 4227 & 1 & 653,000 \\
$\quad$ Import value ('000 SEK) & 411,854 & 4250 & 65,500 & 0 & $10,700,000$ \\
EP: $\ln \left(E P_{i, t}\right)$ & 411,854 & 0.46 & 0.22 & 0.004 & 12 \\
Firm electricity intensity & 411,854 & 0.09 & 0.27 & 0.0001 & 8.12 \\
Weighted tariff: $\tau_{i, p, t}$ & 411,710 & 0.74 & 1.99 & 0 & 57.6 \\
Number of employees: $L_{i, t}$ & 411,854 & 893 & 2491 & 10 & 21,842 \\
Tangible capital (SEK millions): $K_{i, t}$ & 411,854 & 565 & 2130 & 2 & 21,000 \\
\hline
\end{tabular}

Based on observations used in Table 4, column (3)

An asterisk indicates statistical significance at the $1 \%$ level

countries of import origin were either relatively stable or did not increase as rapidly or by as much-see Fig. 2.

In terms of per capita usage, Sweden currently ranks as one of the most electricity-intensive economies with only Iceland, Norway, Canada, and Finland ranking higher. Electricity is the dominant energy source across all manufacturing sectors included in our analysis. ${ }^{12}$ One-third of Swedish industrial energy use in 2008 was electricity with the top six sectors, defined at the 2-digit level, accounting for around $88 \%$ of industrial electricity use. ${ }^{13}$ There is a significant variation in electricity intensity across, as well as within, each of these sectors.

The Swedish government has declared that the economy will reach zero net carbon emissions by 2050 . To reach this objective, policies are being prepared to shift energy use towards more electricity and biofuels. ${ }^{14}$ It is expected that increasingly stringent climate policy will increase the price of Swedish electricity by circa $30 \%$ from current levels in the lead up to $2030 .{ }^{15}$

\section{Data and descriptive statistics}

The firm-level data were obtained from the Swedish Survey of Manufacturers conducted by Statistics Sweden, the Swedish government's statistical agency. We use data for 2001-2008, which covers the universe of Swedish

\footnotetext{
12 The pulp and paper sector generates much of its energy requirements from biomass, which is a byproduct of its production process. For this and other reasons outlined in the data description, we do not include pulp and paper manufacturing firms in our analysis.

13 The most electricity-intense sectors are the pulp, paper and paper products, basic metals, and chemicals and chemical products.

14 See the Swedish Energy Agency's 2014 report on long-term energy scenarios for Sweden, see "Scenarier över Sveriges energisystem: 2014 års 1Ãěngsiktiga scenarier, ett underlag till klimatrapporteringen". Available online: http://www.energimyndigheten.se/.

15 According to the Swedish Energy Agency (Andersson and Gustafsson 2014).
} 
firms. ${ }^{16}$ The survey contains annual observations on output, value-added, employment, capital stocks, investment, and value of other primary factors of production. We use the years 2001 through to 2008 inclusive for our regression analysis, so that we include the 2002-2003 spike in the electricity spot price, and several years after this spike to account for the length of electricity contracts, which have a life up to 3 years long.

We merge these data with customs data on firm-level imports. The customs data allow us to observe the quantity and value of firm imports at the six-digit Common Nomenclature $(\mathrm{CN})$ product level. Our dependent variable is quantity $(\mathrm{kg})$ or value (SEK) of a product imported. Imported quantities/values vary widely across firms and products. The average quantity (value) of a single imported product by a firm is $220 \mathrm{~kg}$ (4.25 million SEK), see Table 1 . In terms of value, total imports per firm make up a significant share of a firm's inputs in a given year, accounting for close to $27 \%$ of the value of materials use on average. ${ }^{17}$

Climate change has been a priority policy area for Sweden over a number of years. One effect of this is that the Swedish government collects detailed data from Swedish firms on their energy consumption. Hence, Statistics Sweden can provide data that include the quantity and cost of electricity paid each year by each firm. The energy survey covers all manufacturing firms with more than 10 employees from the year 2000 onwards. ${ }^{18}$ The annual quantities and costs of electricity are used to derive each firm's EP, defined as the annual average price paid for electricity in SEK/kWh. The average EP incurred by firms is $0.46 \mathrm{SEK} / \mathrm{kWh}$, see Table $1 .^{19}$

We include product-level tariffs in our analysis to control for the impact of tariffs on imports of intermediary inputs. Our weighted tariff variable is computed from the UNCTAD TRAINS database, which includes tariff observations at the six-digit HS level. The weights are based on the value of each product imported by firm $i$ each year. Sweden joined the European Union in 1995 and tariffs have since then been set in Brussels. This mitigates, to a degree, the extent to which Swedish industry has exerted influence on tariff rates. Moreover, the European Union expanded in 2004 with the accession of ten countries: Cyprus, Czech Republic, Estonia, Hungary, Latvia, Lithuania, Malta, Poland, Slovakia, and Slovenia. Trade flow observations from these countries are dropped from the analysis due to the confounding effects of EU integration on imports to Sweden. The top countries of origin for Swedish manufacturing imports are listed in Appendix Table 7.

Another consideration is that EU import tariffs for pulp and paper products were reduced in 2004 under the Accelerated Tariff Liberalization initiative in forest products among members of the WTO. This is a particularly relevant consideration here as the Swedish pulp and paper sector is also the most electricity-intensive sector in

\footnotetext{
16 The data cover 13,298 manufacturing firms classified by the 4-digit NACE Rev.1.1 codes 10.3037.20).

17 The figure of $27 \%$ is computed by taking the ratio of the value of all imports to all material inputs for each firm for a given year.

18 The electricity data are available at the plant level, but we aggregate it to the firm level to match with the import data, which is available only at the firm level.

19 The variation in firm EPs is significant even within narrowly defined sectors-see Appendix Table 5.
} 
Table 2 Pairwise correlations between firm characteristics, 2001

\begin{tabular}{lrrrrrr}
\hline & $\ln \left(x_{f, i, p, t}\right)$ & $\ln \left(\mathrm{EP}_{i, t}\right)$ & el_intensity & $\tau_{i, p, t}$ & $\ln L_{i, t}$ & $\ln K_{i, t}$ \\
\hline $\ln \left(\mathrm{EP}_{i, t}\right)$ & $-0.11^{*}$ & & & & & \\
el_intensity & $0.07^{*}$ & $-0.18^{*}$ & & & & \\
$\tau_{i, p, t}$ & $-0.14^{*}$ & $0.04^{*}$ & $-0.01^{*}$ & & & \\
$\ln L_{i, t}$ & $0.05^{*}$ & $-0.24^{*}$ & $0.03^{*}$ & $-0.08^{*}$ & & \\
$\ln K_{i, t}$ & $0.13^{*}$ & $-0.30^{*}$ & $0.13^{*}$ & $-0.10^{*}$ & $0.87^{*}$ & \\
$K_{-}$intensity & $0.09^{*}$ & -0.06 & $0.29^{*}$ & -0.04 & $0.10^{*}$ & $0.33^{*}$ \\
\hline
\end{tabular}

Based on observations used in Table 4, column (3)

An asterisk indicates statistical significance at the $1 \%$ level

$e l \_$intensity ${ }_{i}$ is computed as the average ratio of the quantity of electricity used in kWh to value added in 2001

$K \_$intensity ${ }_{i}$ is computed as the average ratio of the quantity of tangible capital to firm output in 2001

over the observed life of the firm

Table 3 Pairwise correlation within-firm characteristics, 2001-2006 first differences

\begin{tabular}{lcccc}
\hline & $\Delta \ln \left(x_{f, i, p, t}\right)$ & $\Delta \ln \left(\mathrm{EP}_{i, t}\right)$ & $\Delta \tau_{i, p, t-1}$ & $\Delta \ln L_{i, t}$ \\
\hline$\Delta \ln \left(\mathrm{EP}_{i, t}\right)$ & -0.00 & & & \\
$\Delta \tau_{i, p, t-1}$ & $-0.06^{*}$ & 0.01 & & \\
$\Delta \ln L_{i, t}$ & $0.07^{*}$ & $-0.02^{*}$ & 0.01 & \\
$\Delta \ln K_{i, t}$ & $0.03^{*}$ & -0.02 & 0.00 & $0.53^{*}$ \\
\hline
\end{tabular}

Based on observations used in Table 4, column (3)

An asterisk indicates statistical significance at the $1 \%$ level

Sweden. Another concern is that the pulp and paper sector produces a significant amount of its own electricity, which is not reported in the Statistics Sweden data set. Hence, the pulp and paper sector is omitted to ensure that the results are not influenced by self-generation or are not being driven by trade liberalization.

The correlation coefficients for electricity costs and other firm-level variables for a 2001 cross-section are provided in Table 2. The correlation coefficients indicate that firm input electricity costs are negatively correlated with the value of imports and firm size proxied by employees and capital for the cross-section of firms. The cross-section correlations raise the concern that any finding of a negative relationship between electricity prices and imports over time in our regressions may be spuriously driven by firm growth. In response to this concern, we report the withinfirm correlation coefficients for electricity costs and other firm-level variables using 2001-2006 first differences in Table 3. The within-firm correlations paint a much different picture, with much lower correlation between electricity prices and firm size over time, and no statistically significant correlation between electricity prices and imports within firms over time. These correlations underscore the importance of controlling for firm characteristics in the regression analysis. 
In sum, the data which we use for our analysis includes all manufacturing firms in Sweden, excluding: firms with less than ten employees; the pulp and paper sector; and imports from the countries that acceded to the EU in 2004.

\section{Analysis}

We test the hypothesis using a panel regression that spans years 2001 and 2008 inclusive. We use the variation in changes over time of firm-level EPs and an unexpected increase in the electricity spot price to identify the effect on the products imported by these firms. The regressions take the following form:

$$
\begin{aligned}
\ln \left(x_{f, i, p, t}\right)= & \beta_{1} \ln \left(\mathrm{EP}_{i, t-1}\right)+\sum_{r=2}^{4} \beta_{r}\left\{\ln \left(\mathrm{EP}_{i, t-1}\right) \times I_{r}\right\} \\
& +\eta_{3} Z_{i, p, t}+D_{i, p}+D_{s, t}+\varepsilon_{i, p, t},
\end{aligned}
$$

where depending on the specification, the dependent variable $x_{f, i, p, t}$ denotes the imported value (SEK) or quantity $(\mathrm{kg})$ of product $p$ by firm $i$ in year $t ; \ln \left(\mathrm{EP}_{i, t-1}\right)$ is the annual unit value electricity price paid by firm $i$ lagged by 1 year; $I_{r}$ is an binary variable indicating the electricity intensity quartile of firm $i$. On average, each firm imports 80 distinct products, and $D_{i, p}$ captures the firm-product fixed effects. $D_{s, t}$ captures year-sector fixed effects, which are an interaction between year dummies and sectoral dummies defined at the two-digit NACE rev. 2 level. $D_{s, t}$ controls for industry-specific shocks that may drive import patterns. We include firm-product and year-sector fixed effects in all specifications. Note that we cannot include product fixed effects, since our variable of interest, electricity intensity of each imported product, is product-specific. $Z_{i, p, t}$ is a vector of controls such as each firm's weighted tariff, workers, and capital employed by the firm. The uninteracted quartile indicators are subsumed by the firm-product fixed effects.

Our main variable of interest is the interaction of firm-level EP with firm-level electricity intensity, $\ln \left(\mathrm{EP}_{i, t-1}\right) \times I_{r}$. Firms' electricity intensity is calculated as the quantity of electricity used by the firm, in kWh, divided by the same firm's value-added, averaged over all observed years of the firm's life. We use the average lifetime electricity intensity, so that we can interpret changes to imports over time holding firms' electricity intensity constant. The dummy variable $I_{r}$ is then computed using this average electricity intensity: $I_{4}=1$ denotes the quartile of firms with the highest electricity intensity. We lag EP by 1 year to help mitigate endogeneity, e.g., firm imports and firm EP may increase simultaneously if the firm faces a positive firm specific demand shock. The most electricity-intense sectors are listed in Appendix Table 8.

A statistically significant and negative point estimate of the linear combination of $\beta_{1}+\beta_{4}$ would indicate support for our hypothesis that: electricity-intense firms have a lower propensity to increase imports in response to a domestic electricity price increase. We have import data in kilograms as well as the value imported in SEK and we use both measures in our analysis. However, our preferred 
Table 4 Impact of increasing electricity costs on firm-level imports across the distribution of firm electricity intensity, all firms

\begin{tabular}{llll}
\hline Dependent var.: $\ln \left(x_{M, i, p, t}\right)$ & $\mathrm{kg}(1)$ & $\mathrm{kg}(2)$ & $\mathrm{SEK}(3)$ \\
\hline $\ln \left(\mathrm{EP}_{i, t-1}\right)$ & $-0.043(0.029)$ & $-0.044(0.029)$ & $-0.046(0.026)^{*}$ \\
$\quad \times I_{r=2}$ & $0.079(0.033)^{* *}$ & $0.077(0.033)^{* *}$ & $0.097(0.029)^{* * *}$ \\
$\quad \times I_{r=3}$ & $-0.057(0.037)$ & $-0.059(0.037)$ & $-0.083(0.033)^{* *}$ \\
$\quad \times I_{r=4}$ & $-0.166(0.038)^{* * *}$ & $-0.164(0.038)^{* * *}$ & $-0.108(0.033)^{* * *}$ \\
$\tau_{i, p, t-1}:$ weighted tariff & & $-0.038(0.005)^{* * *}$ & $-0.031(0.005)^{* * *}$ \\
Observations & 203,872 & 203,848 & 203,848 \\
Overall $R^{2}$ & 0.004 & 0.005 & 0.007 \\
\hline
\end{tabular}

The dependent variable is the firm's imported product measured in kilograms or in SEK

$* p<0.10, * * p<0.05$, *** $p<0.01$. Robust standard errors in parentheses

Firm-product and year-two-digit-sector fixed effects included in all specifications

Table 5 Impact of increasing electricity costs on firm-level imports excluding firm entry and exit

\begin{tabular}{llll}
\hline Dependent var.: $\ln \left(x_{M, i, p, t}\right)$ & $\mathrm{kg}$ & $\mathrm{kg}$ & $\mathrm{SEK}$ \\
\hline $\ln \left(\mathrm{EP}_{i, t-1}\right)$ & $0.011(0.032)$ & $0.010(0.032)$ & $-0.007(0.029)$ \\
$\quad \times I_{r=2}$ & $0.072(0.035)^{* *}$ & $0.070(0.035)^{* *}$ & $0.087(0.031)^{* * *}$ \\
$\quad \times I_{r=3}$ & $-0.044(0.039)$ & $-0.046(0.039)$ & $-0.064(0.034)^{*}$ \\
$\quad \times I_{r=4}$ & $-0.158(0.040)^{* * *}$ & $-0.156(0.040)^{* * *}$ & $-0.103(0.034)^{* * *}$ \\
$\tau_{i, p, t-1}:$ weighted tariff & & $-0.038(0.006)^{* * *}$ & $-0.032(0.005)^{* * *}$ \\
Observations & 173,291 & 173,291 & 173,291 \\
Overall $R^{2}$ & 0.006 & 0.007 & 0.012 \\
\hline
\end{tabular}

The dependent variable is the firm's imported product measured in kilograms or in SEK

$* p<0.10, * * p<0.05, * * * p<0.01$. Robust standard errors in parentheses

Firm-product and year-two-digit-sector fixed effects included in all specifications

specification is for imports denominated in kilograms: this yields $\beta_{r}$ coefficients that can be interpreted as elasticities of quantity demand and helps to mitigate the influence of changes in import unit values due to foreign cost shocks, pricing to market and exchange rate fluctuations that may bias our results.

Table 4 presents the baseline OLS regression results including all firms. The dependent variable $\ln \left(x_{M, i, p, t}\right)$ is denominated in kilograms under columns (1) and (2). In column (1), import response across firms' electricity intensity is heterogeneous. To facilitate interpreting the coefficients, we present the conditional effect of the EP increase on each energy intensity quartile. Thus, firm imports in the lowest energy intensity quartile have a statistically insignificant response to the electricity price. However, firms with the highest energy intensity responded to the electricity price increase by decreasing their imports. The point estimate for these most electricity-intense firms is the linear combination of the estimated coefficient for the first and fourth energy intensity quartiles, or $\beta_{1}+\beta_{4}$ from Eq. (6), which is $-0.043-0.123=-0.166$ and statistically significant at the $1 \%$ 
Table 6 Robustness to firm characteristics

\begin{tabular}{|c|c|c|c|c|}
\hline \multirow{2}{*}{$\begin{array}{l}\text { Dependent var.: } \\
\ln \left(x_{M, i, p, t}\right) \text { in } \mathrm{kg}\end{array}$} & \multicolumn{4}{|l|}{$I_{r}^{\prime}$} \\
\hline & (1) & (2) & (3) & (4) \\
\hline $\ln \left(\mathrm{EP}_{i, t-1}\right)$ & $-0.039(0.030)$ & $-0.056(0.029)^{*}$ & $-0.051(0.029)^{*}$ & $-0.017(0.039)$ \\
\hline$\times I_{r=2}$ & $0.071(0.034)^{* *}$ & $0.069(0.033)^{* *}$ & $0.077(0.033)^{* *}$ & $0.112(0.042)^{* * *}$ \\
\hline$\times I_{r=3}$ & $-0.067(0.035)^{*}$ & $-0.019(0.037)$ & $-0.041(0.037)$ & $-0.014(0.050)$ \\
\hline$\times I_{r=4}$ & $-0.118(0.036)^{* * *}$ & $-0.092(0.038)^{* *}$ & $-0.149(0.038)^{* * *}$ & $-0.105(0.057)^{*}$ \\
\hline$L_{i, t-1}:$ employees & & $0.392(0.033)^{* * *}$ & & \\
\hline$K_{i, t-1}:$ capital stock & & & $0.105(0.017)^{* * *}$ & \\
\hline $\ln \left(\mathrm{EP}_{i, t-1}\right) \times I_{v=1}^{K}$ & & & & $0.000()$. \\
\hline$\times I_{v=2}^{K}$ & & & & $-0.041(0.045)$ \\
\hline$\times I_{v=3}^{K}$ & & & & $-0.045(0.049)$ \\
\hline$\times I_{v=4}^{K}$ & & & & $-0.080(0.055)$ \\
\hline $\begin{array}{l}\tau_{i, p, t-1}: \text { weighted } \\
\text { tariff }\end{array}$ & $-0.037(0.005)^{* * *}$ & $-0.037(0.005)^{* * *}$ & $-0.037(0.005)^{* * *}$ & $-0.038(0.005)^{* * *}$ \\
\hline Observations & 203,848 & 203,848 & 203,848 & 203,848 \\
\hline Overall $R^{2}$ & 0.004 & 0.007 & 0.005 & 0.005 \\
\hline
\end{tabular}

The dependent variable is the firm's imported product measured in $\mathrm{kg}$

In column (1), firm intensity is defined at the beginning of the firm's life

$* p<0.10, * * p<0.05$, *** $p<0.01$. Robust standard errors in parentheses

firm-product and year-two-digit-sector fixed effects included in all specifications

level. This suggests that firms in the highest energy intensity quartile decrease their imports as the EP they face increases. Subjecting these energy intense firms to a 30\% increase in EP would lead to a 5\% decrease in the firm's imported quantity. In contrast, firms in the second electricity intensity quartile increase their imports in EP: a 30\% increase in EP would lead these firms to increase imports by $2.4 \%$. The tariff control is added in column (2). The point estimate for $\tau_{i, p, t-1}$ is negative and statistically significant as expected. Our result for the most electricity-intense firms $\left(\beta_{1}+\beta_{4}\right)$ is robust to the tariff control. The results for the dependent variable $\ln \left(x_{M, i, p, t}\right)$ in terms of import values (SEK) are under column (3). The results are qualitatively analogous to the results under columns (1) and (2), except that the estimates for the third quartile are now statistically significant.

Table 5 presents the baseline regression restricting the sample to only those firms that survive all years, 2001-2008. Restricting the sample in this way removes the impact of firm entry and exit on the point estimates. The results are similar to those summarized in Table 4, which suggests that our main results are not driven by firm entry and exit.

Firm's import response is heterogeneous across electricity intensity quartiles: firms with a higher electricity intensity reduce their imports, whereas firms with a lower electricity intensity increase their imports. If Sweden's climate policy increases electricity prices by $30 \%$, as it is expected to, then the lowest and highest electricity-intense firms would increase imports by $2.3 \%$ and decrease imports 
$5 \%$, respectively. The quality of our data allows us to identify statistically significant, albeit economically small, heterogeneous effects. Studies using more aggregate data would not capture these effects if positive and negative estimates cancel. Firm electricity intensity is an important factor in determining the firm's propensity to use imports to mitigate an EP shock.

In Table 6, we examine a number of alternative specifications to further test the robustness of our results. The dependent variable $\left(x_{M, i, p, t}\right)$ is denominated in kilograms. A potential concern is that our measure of the firm's electricity intensity, averaged over the firm's lifetime, is endogenously determined. We, therefore, examine an alternative specification where we compute the firm's electricity intensity for the observed first year of the firm's life: the ratio of the electricity consumed to the firm's value added for the year. We then use this measure of electricity intensity as the basis for sorting the firms into quartiles $I_{r}^{\prime}$, which are interacted with the firm's own EP. The results of the regression are presented in Table 6 column (1). The results are stable under this alternative specification.

Another potential concern is that our results are driven by firm size. Firms that grow, for example, may be able to negotiate better electricity contracts, and Table 3 indicates that electricity prices are negatively correlated with firm size. In Table 6 column (2), we revert to our preferred definition of $I_{r}$ and include logged number of employees lagged by 1 year as a control firm size. Employment is positively associated with imports with a statistically significant point estimate as expected. The estimate of $\beta_{1}+\beta_{4}$ remains negative, albeit less negative, and significant, although the statistical significance drops from 1 to $5 \%$.

A mechanism that has been put forward in the literature to explain the lack of import response amongst energy/pollution-intensive industries is that they are capital intensive and thereby immobile or not 'footloose', see Ederington et al. (2005). The results which we report could be driven by the footloose mechanism: if capital intensity and electricity intensity are correlated, then our results might simply be reconfirming the footloose hypothesis. We, therefore, check whether our results are robust to controlling for capital. We do this in two ways. For the first approach, we control for the tangible capital employed by the firm. These results are presented in Table 6 under column (3), where we introduce a control for logged tangible capital used by the firm lagged by one year. This is another measure of firm size. The point estimate for capital is positive and statistically significant; however, our negative point estimate for $\beta_{1}+\beta_{4}$ remains statistically significant at the $1 \%$ level. The fact that our results are robust to controlling for firm size in terms of employees and tangible capital suggests that our results are not being spuriously driven by the fact that firms that grow pay less for electricity and also import more.

For the second approach, we sort the firms into capital intensity quartiles, similar to the approach used to compute firm-level electricity intensity. We compute capital intensity as the firm's tangible capital in SEK divided by the same firm's value added, averaged over all years the firm is alive. We use the average lifetime tangible capital intensity, so that we can interpret changes to imports over time holding firms' capital intensity constant. We sort the firms into quartiles of capital intensity, which we capture with the dummy variable $I_{v}^{K}$. With this specification, we check whether or not our interaction with electricity intensity is not driven by the underlying capital 
intensity of firms and thereby examine the robustness of the capital intensity/footloose hypothesis that has been put forward by earlier work. Capital intensity and electricity intensity are correlated, but not perfectly, see Table 2 . The results of this regression are presented in Table 6 column (4). The capital intensity controls are not statistically significant, although we note that the point estimate for the most capital intense quartile is negative at -0.08 , suggesting that there is some weak support for the capital intensity/footloose hypothesis. Nonetheless, our main results continue to hold: although the point estimate for $\beta_{1}+\beta_{4}$ becomes less negative and statistical significance falls to the $10 \%$ level.

There is a non-monotonic relationship between the electricity intensity of the firm and the propensity to import in EP. Across the specifications tested, we find consistently that it is the second electricity intensity quartile that increased their imports most. Firms in this quartile substitute towards imports more readily. This intensity quartile is dominated by the 'Machinery' and 'Motor vehicles' sectors, see Appendix Table 9. Taking our mechanism at face value, our positive estimates for the second electricity intensity quartile suggest that these two sectors can readily incorporate foreign inputs in their production process (substitution effect), and that demand for the firm output is relatively unaffected (scale effect).

There are several potential reasons why we find quantitatively small impacts. First, the largest and most electricity-intense firms likely engaged in hedging strategies that insulated themselves against the rise in electricity prices. Second, firms may not have believed the increase in electricity prices to be temporary and thus opted to not pursue any adaptations. In this sense, our estimates may be viewed as a lower bound on impact of a carbon tax on leakage. Climate policy leakage via trade flows is the leakage mechanism which we focus on, and climate policy effects on trade in final goods lie outside the scope of our analysis.

Finally, a potential concern is that electricity prices are endogenously determined by imports or that imports and electricity prices are jointly determined by the level of economic activity at the aggregate level. Our use of industry-year fixed effects arguably absorbs the aggregate impact of imports on average electricity prices. Industry-year fixed effects also absorb spurious positive correlation at the aggregate level between imports and electricity prices related to the business cycle.

\section{Conclusions}

We use an unexpected increase in Swedish electricity spot price that took place in 2002-2003 to evaluate the impact of higher firm-level EPs for Swedish manufacturers on importing. Our empirical analysis clarifies the role that the ease of substitutability between domestic and foreign inputs plays in determining firm-productlevel imports, and can help to reconcile counter-intuitive results in the literature that examines leakage via imports in energy or pollution-intensive products. We show how the substitutability of domestic and foreign inputs in production, and the firm's electricity intensity, can reverse the sign of the impact of higher energy prices on the pattern of imports. In the short-run, substitution towards foreign inputs is difficult 
and that the scale effect dominates the substitution effect for energy-intense firms. This suggests that short-run climate policy leakage effects from importing may be lower than predicted if the parameters for substitution elasticities are too high.

Our results have implications for the design of 'response measures' to climate policy. Proposed response measures are partly motivated as a means to mitigate carbon leakage resulting from unilateral climate policy and seek to protect energy-intensive trade-exposed sectors; see, for example, the EU Commission's leakage list. ${ }^{20}$ Our analysis shows that firms' ability to substitute between domestic and foreign inputs is critical in determining the propensity for policy leakage to occur and should be considered when estimating the degree to which firms are exposed to leakage and the exceptions which they receive from domestic climate policy.

Acknowledgements Financial support from the Jan Wallander and Tom Hedelius Foundation, the Marianne and Marcus Wallenberg Foundation, and the Erling-Persson Family Foundation is gratefully acknowledged. We also acknowledge Josh Ederington, Rikard Forslid, Richard Friberg, Henrik Horn, and Jim Markusen for comments on this work.

Open Access This article is distributed under the terms of the Creative Commons Attribution 4.0 International License (http://creativecommons.org/licenses/by/4.0/), which permits unrestricted use, distribution, and reproduction in any medium, provided you give appropriate credit to the original author(s) and the source, provide a link to the Creative Commons license, and indicate if changes were made.

\section{Appendix}

See Figs. 3, 4, 5 and Tables 7, 8 and 9.

${ }^{20}$ The EU Commission's leakage list is available online at: http://ec.europa.eu/clima/ and will apply over the years 2015-2019 inclusive. 


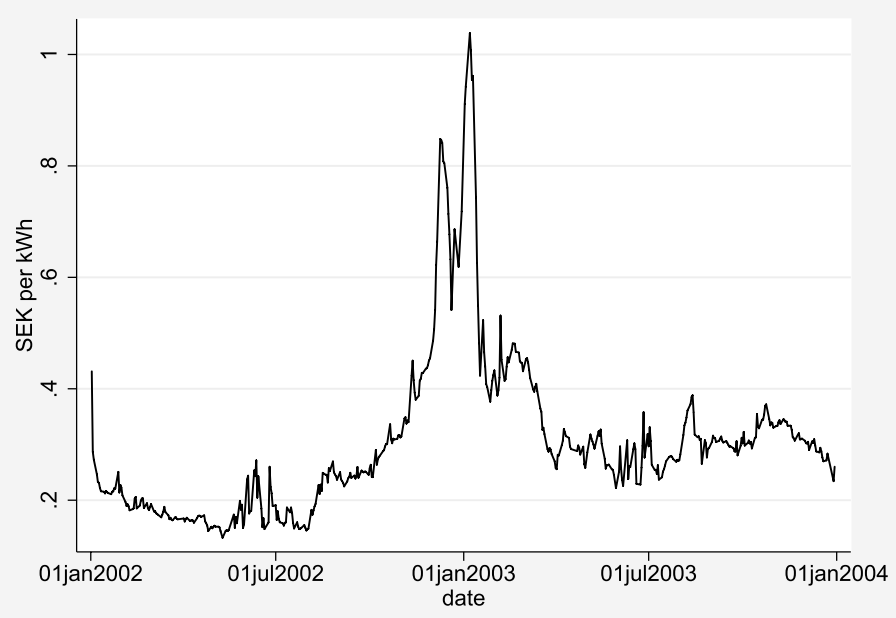

Fig. 3 The electricity spot price in Sweden over the years 2002-2003. Source: Nordpool

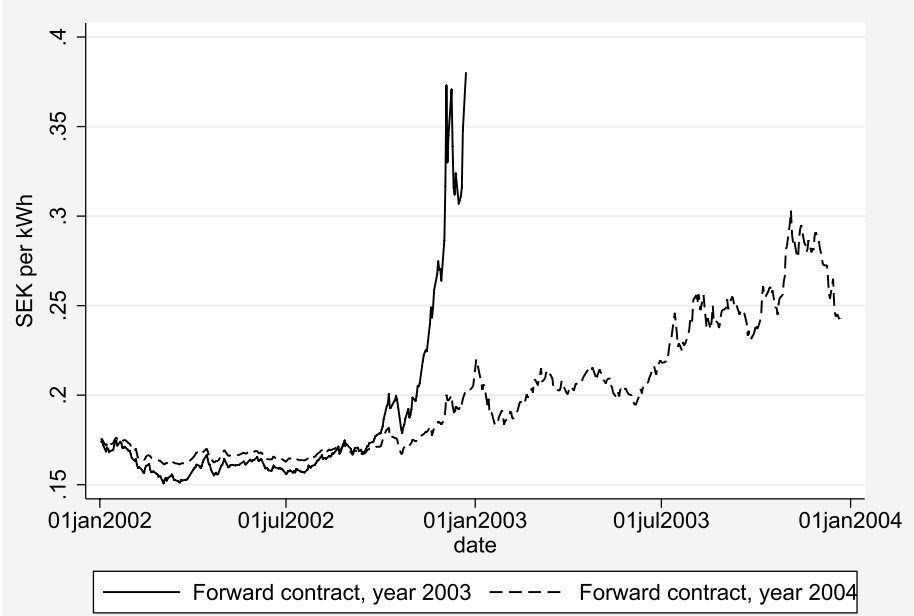

Fig. 4 The price of electricity forward contracts in Sweden over the years 2001-2003. Source: Nordpool 


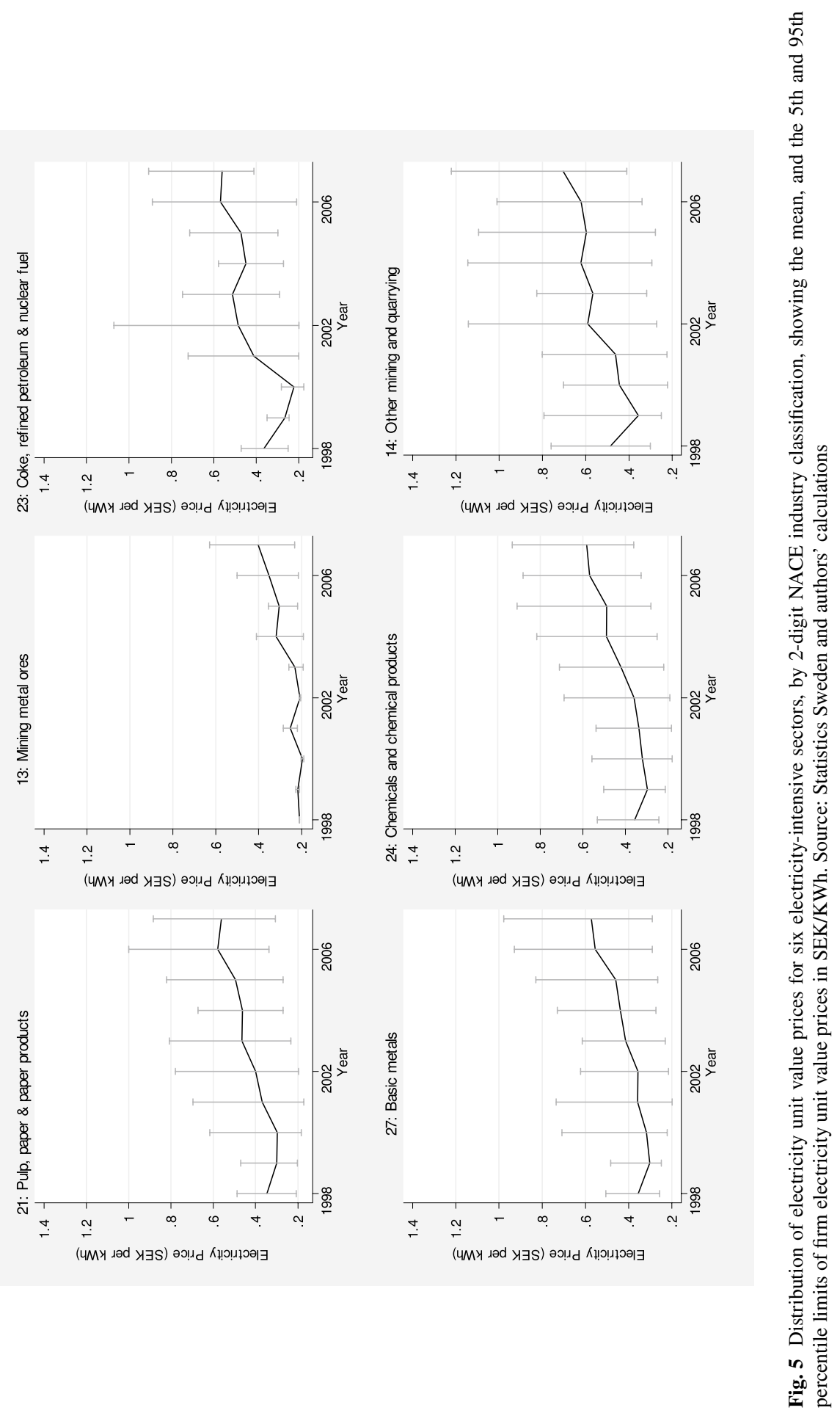


Table 7 Ranking of top countries of origin for imports to Sweden by manufacturing firms, by quantity (kg), and by value

\begin{tabular}{llll}
\hline Country code & Country & $\begin{array}{l}\text { Rank by kg } \\
\text { imported }\end{array}$ & $\begin{array}{l}\text { Rank } \\
\text { by SEK } \\
\text { imported }\end{array}$ \\
\hline FI & Finland & 1 & 6 \\
DE & Germany & 2 & 1 \\
NO & Norway & 3 & 7 \\
DK & Denmark & 4 & 2 \\
NL & Netherlands & 5 & 4 \\
GB & UK & 6 & 3 \\
RU & Russia & 7 & 19 \\
BE & Belgium & 8 & 9 \\
FR & France & 9 & 5 \\
CN & China & 10 & 10 \\
IT & Italy & 11 & 11 \\
US & USA & 12 & 8 \\
ES & Spain & 13 & 14 \\
BR & Brazil & 14 & 25 \\
AT & Austria & 15 & 17 \\
\hline Ra & &
\end{tabular}

Based on observations used in Table 4, column (3)

Table 8 Sweden's most electricity-intensive sectors during the year 2001

\begin{tabular}{lll}
\hline Electricity intensity & Industry SNI2007 & Description \\
\hline 21.28 & 20,150 & Fertilisers and nitrogen compounds \\
1.27 & 11,060 & Malt \\
1.26 & 19,200 & Manufacture of refined petroleum products \\
1.22 & 17,113 & Sulphite pulp \\
1.00 & 20,130 & Inorganic base chemicals \\
0.93 & 24,420 & Aluminium production \\
0.79 & 20,600 & Man-made fibres \\
0.67 & 26,110 & Electronic components \\
0.65 & 20,160 & Plastics in primary forms \\
0.56 & 23,510 & Cement \\
0.51 & 10,410 & Oils and fats \\
0.41 & 16,210 & Veneer sheets and wood-based panels \\
0.41 & 23,140 & Glass fibers \\
0.41 & 24,510 & Iron \\
0.39 & 13,300 & Finishing of textiles \\
\hline
\end{tabular}

Based on observations used in Table 4, column (3) 
Table 9 The frequency of firms by electricity intensity quartile and two-digit sector

\begin{tabular}{|c|c|c|c|c|c|c|}
\hline \multirow[t]{2}{*}{ Description } & \multirow[t]{2}{*}{ SNI 2007 code } & \multicolumn{4}{|c|}{ Electricity intensity quartile } & \multirow[t]{2}{*}{ Total } \\
\hline & & 1 & 2 & 3 & 4 & \\
\hline Food products & 10 & 2133 & 3839 & 13,541 & 13,727 & 33,240 \\
\hline Beverages & 11 & 44 & 1712 & 2399 & 256 & 4411 \\
\hline Tobacco & 12 & 239 & 94 & 90 & 0 & 423 \\
\hline Textiles & 13 & 2265 & 3046 & 3766 & 2515 & 11,592 \\
\hline Wearing apparel & 14 & 3324 & 1033 & 2135 & 7 & 6499 \\
\hline Leather & 15 & 301 & 405 & 736 & 85 & 1527 \\
\hline Wood products & 16 & 830 & 1018 & 1815 & 3284 & 6947 \\
\hline Printing & 18 & 1251 & 435 & 1116 & 668 & 3470 \\
\hline Coke/refined petro. & 19 & 189 & 0 & 302 & 1515 & 2006 \\
\hline Chemicals & 20 & 8086 & 8089 & 11,018 & 13,677 & 40,870 \\
\hline Pharmaceuticals & 21 & 3997 & 1616 & 2346 & 572 & 8531 \\
\hline Rubber and plastics & 22 & 2426 & 3081 & 6113 & 14,453 & 26,073 \\
\hline Non-metallic minerals & 23 & 1728 & 2879 & 3570 & 7304 & 15,481 \\
\hline Basic metals & 24 & 371 & 1096 & 2035 & 17,758 & 21,260 \\
\hline Fabricated metals & 25 & 8819 & 9493 & 11,484 & 7712 & 37,508 \\
\hline Computer/electronics & 26 & 12,253 & 8734 & 5725 & 2379 & 29,091 \\
\hline Electricals & 27 & 10,268 & 5759 & 5652 & 5437 & 27,116 \\
\hline Machinery & 28 & 28,860 & 21,254 & 12,900 & 3393 & 66,407 \\
\hline Motor vehicles & 29 & 3859 & 13,765 & 6873 & 5714 & 30,211 \\
\hline Transport equipment & 30 & 4034 & 7543 & 3473 & 1134 & 16,184 \\
\hline Furniture & 31 & 1902 & 3814 & 3350 & 862 & 9928 \\
\hline \multirow[t]{2}{*}{ Other } & 32 & 5857 & 4546 & 2508 & 168 & 13,079 \\
\hline & Total & 103,036 & 103,251 & 102,947 & 102,620 & 411,854 \\
\hline
\end{tabular}

The electricity intensity quartiles are identically defined in all regressions

Electricity intensity computed using the average over the observed life of the firm

Based on observations used in Table 4, column (3). Quartile 4 denotes the highest electricity intensity

\section{References}

Aichele R, Felbermayr G (2015) Kyoto and carbon leakage: an empirical analysis of the carbon content of bilateral trade. Rev Econ Stat 97:104-115

Aldy JE, Pizer WA (2015) The competitiveness impacts of climate change mitigation policies. J Assoc Environ Resour Econ 2:565-595

Andersson A, Gustafsson AP (2014) Scenarier över Sveriges energisystem: 2014 års långsiktiga scenarier, ett underlag till klimatrapporteringen Technical Report ER 2014:19. Swedish Energy Agency, Sweden

Baylis K, Fullerton D, Karney DH (2014) Negative leakage. J Assoc Environ Resour Econ 1:51-73

Branger F, Quirion P (2014) Would border carbon adjustments prevent carbon leakage and heavy industry competitiveness losses? Insights from a meta-analysis of recent economic studies. Ecol Econ 99:29-39

Cherniwchan J, Copeland BR, Taylor MS (2017) Trade and the environment: new methods, measurements, and results. Annu Rev Econ 9:59-85 
Chevallier FB, Philippe Quirion J (2017) Carbon leakage and competitiveness of cement and steel industries under the EU ETS: much ado about nothing. Energy J 37

Cole MA, Elliott RR, Okuibo T, Zhang L (2017) The pollution outsourcing hypothesis: an empirical test for Japan. Discussion papers 17096, Research Institute of Economy, Trade and Industry (RIETI)

Ederington J, Levinson A, Minier J (2005) Footloose and pollution-free. Rev Econ Stat 87:92-99

Fell H (2010) EU-ETS and nordic electricity: a CVAR analysis. Energy J 31:1-25

Levinson A (2010) Offshoring pollution: is the United States increasingly importing polluting goods? Rev Environ Econ Policy 4:63-83

Levinson A, Taylor M (2008) Unmasking the pollution haven effect. Int Econ Rev 49:223-254

Monjon S, Quirion P (2010) How to design a border adjustment for the European Union emissions trading system? Energy Policy 38:5199-5207

Nagatani K (1978) Substitution and scale effects in factor demands. Can J Econ 11:521-527 